\title{
Meteorological Extremes in Korea: Prediction, Assessment, and Impact
}

\author{
Okjeong Lee ${ }^{1}$ and Sangdan Kim ${ }^{2, *(\mathbb{D})}$ \\ 1 School of Integrated Science for Sustainable Earth \& Environmental Disaster, Pukyong National University, \\ Busan 48513, Korea; okjeong_2@pukyong.ac.kr \\ 2 Department of Environmental Engineering, Pukyong National University, Busan 48513, Korea \\ * Correspondence: skim@pknu.ac.kr; Tel.: +82-51-629-6529
}

Citation: Lee, O.; Kim, S.

Meteorological Extremes in Korea:

Prediction, Assessment,

and Impact. Atmosphere 2021, 12, 782.

https://doi.org/10.3390/atmos1206078

Received: 2 June 2021

Accepted: 14 June 2021

Published: 18 June 2021

Publisher's Note: MDPI stays neutral with regard to jurisdictional claims in published maps and institutional affiliations.

Copyright: (C) 2021 by the authors. Licensee MDPI, Basel, Switzerland. This article is an open access article distributed under the terms and conditions of the Creative Commons Attribution (CC BY) license (https:/ / creativecommons.org/licenses/by/ $4.0 /$ ).
The extreme climates that occur around the world every year have a profound impact on the quality of life for mankind since they can cause natural disasters beyond our control, such as droughts and floods. Engineering-based experts are needed to strengthen the ability to predict the location, spatial extent, severity, and ultimately social impact of these extreme events. In addition, humanities and sociology-based administrative skills are required in order to more effectively communicate disaster warning messages to the general public or to properly formulate and implement disaster response plans. This special issue of Atmosphere focuses on extreme climate phenomena in Korea. In particular, it is composed of studies pursuing practical approaches that can be applied immediately in all social environments in Korea. This special issue also includes studies dealing with adaptation to global warming, studies investigating the impact of extreme climates on people and the environment, and discussions of disaster response systems (including vulnerability assessment systems).

This editorial provides a brief introduction to the papers belonging to this special issue. The published papers are classified according to the category of disaster as follows: four papers on drought, three papers on temperature, three papers on oceans, two papers on floods, one paper on annual precipitation, and one paper on hydrology.

Four papers in the field of drought have been published. The first paper in the field of drought was written by Won et al. [1]. The authors pointed out that studies related to the existing copula-based multivariate drought frequency analysis conducted in Korea provide return levels lacking reality for past drought events. As an improvement or alternative to this, a procedure using partial duration series and bi-variate exponential distribution is introduced as two methods to quantify the return levels of past drought events in Korea. They derive a drought severity-duration-frequency curve from the two methods of frequency analysis and use this curve to investigate how the ongoing drought phenomenon is evolving. It also provides information on future extreme drought behavior in Korea under the conditions of various future climate change scenarios using two approaches. The second paper in the field of drought is by Lee et al. [2]. In this paper, they tried to quantitatively define the extreme drought in the region using factors that are realistically acceptable. After constructing five factors (period, consecutive years, water availability, return level, and regional experience) indicating severe drought, the proposed procedure was applied to the drought events that occurred in Korea between 2014 and 2015 and analyzed. A third paper in the field of drought is by Sattar et al. [3]. In this paper, the concept of drought propagation was introduced to explain the interdependence between meteorological drought and hydrological drought. The Markov Bayesian Classifier (MBC) was used to probabilistically assess meteorological and hydrological droughts. When predicting meteorological drought, the accuracy of the MBC model varied from $36 \%$ to $76 \%$, and when predicting hydrological drought the accuracy ranged from $33 \%$ to $70 \%$. The authors argue that considering drought propagation is very useful for the planning, 
monitoring, and mitigation of hydrological droughts in areas with limited availability of hydrological data. The last paper in the field of drought was by Mun et al. [4]. In this paper, the authors investigated vulnerability to agricultural drought in Korea based on exposure, sensitivity, and adaptability. They analyze the vulnerability of agricultural reservoirs to drought and present a vulnerability map created by applying the climate change vulnerability framework. Vulnerability is divided into four levels. The western regions of Korea are very vulnerable to climate and agricultural reservoir factors, and the eastern regions have been shown to be less adaptable. The calculated results are expected to contribute to a proactive response to agricultural drought.

Four papers in the field of temperature have also been published. The first paper in the field of temperature was by Tran et al. [5]. In this study, the authors used deep learning to predict the maximum daily temperature, and applied meta-learning using genetic algorithms to optimize the hyperparameters of the deep learning architecture. It is reported that the hybrid model combining LSTM network and GA outperforms other models in predicting the maximum daily temperature with long lead times. Accurate predictions of the maximum daily temperature are expected to help prepare countermeasures against urban heat wave events in the summer months. The second paper in the field of temperature is by Kim et al. [6]. This study is a case study of the 2016 Korean Peninsula heatwave, using numerical prediction experiments to investigate the impact of the atmosphere-ocean combination on medium-range forecasts. The results presented in this study show that atmosphere-ocean coupling can be an important way to improve the predictive performance of deterministic models when lead times increase beyond several days. The last paper in the field of temperature was by Jo et al. [7]. In this study, the authors explored future changes in Korea's agricultural climate and extreme heat waves at $2{ }^{\circ} \mathrm{C}$ and $3{ }^{\circ} \mathrm{C}$ global warming levels through CORDEX-EA Phase 2 predictions. The increase in average temperature due to global warming has been shown to have a positive effect, such as extending the growth period of vegetables and crops and the expansion of cultivable areas, as well as negative effects due to the shortening of the growth period for reproduction. In addition, it is predicted that the main type of extreme heat wave would be dominated by an abnormal temperature phenomenon that covers the whole of Korea.

Three papers have been published in the field of oceanography. The first paper in the field of oceanography is by Watson and Lim [8]. This study adds two years of data to 2019 , updating the preceding study to provide additional robustness to the new threats associated with sea level rise around the Korean Peninsula. In particular, the authors identified two regions in the east and west of the Korean Peninsula (around Ulleungdo and Gyeonggi Bay in the Yellow Sea) around $37.5^{\circ}$ north latitude in relation to the trend of sea level rise according to satellite altimetry. It is reported that the rate of increase in the region is much higher than the global average trend. The second paper in the field of oceanography is by Song and Cho [9], which modeled the maximum tsunami height using Bayesian neural networks. Until now, tsunami studies have focused on the development of numerical models. However, this study is meaningful from the point of view of utilizing the recently popular artificial intelligence for tsunami prediction. The last paper in the field of oceanography was by Sung et al. [10]. In this study, regional Sea Level Rise (SLR) and Sea Surface Temperature (SST) changes around the Korean Peninsula were estimated. SSP1-2.6 and SSP5-8.5 scenarios and nine CMIP6 model simulations were used to estimate changes in SLR and SST. The authors report that the discrepancy between global and regional changes is more pronounced in SST than in SLR.

Two papers in the flood field have been published. The first paper in the flood field is by Kim and Han [11], who connect hydraulic modeling and machine learning approaches for predicting and responding to extreme floods. The methodology proposed in this study is a combination of a dynamic numerical analysis model, DAMBRK, and a random forest regression technique. The authors claimed that using the proposed technique, a flood map could be generated in less than a minute. If these technologies are implemented in the field, it is expected to help to establish disaster countermeasures considering various flood 
scenarios by quickly providing flood information to disaster-related organizations. The second paper in the flood field is by Seo et al. [12]. While interest in future extreme rainfall is increasing, the lack of consistency of simulated future rainfall outputs from climate models makes it difficult to establish climate change adaptation measures for flooding. Therefore, in this study, a methodology was proposed to investigate future extreme rainfall using the future surface air temperature or dew-point temperature. Compared to conventional methods that use only future rainfall data, it has been found that the proposed method can reduce the uncertainty of the future extreme rainfall output. In addition, Bayesian inference was used to quantify the confidence interval for the rate of change of extreme rainfall in the future.

In addition to the papers introduced above, Lim et al. [13] analyzed the effect of climate change on annual precipitation in Korea using data screening techniques and climate change scenarios and Sun et al. [14] also analyzed the reversibility of hydrological reactions in East Asia from CO2-Derived Climate Change based on CMIP6 simulation.

Overall, this special issue dealt with various natural disasters that occur due to extreme climates. We would like to express our great gratitude for the valuable contributions of the authors. We hope that this special issue will help to lay the scientific foundation for better coping with the changing climate.

Author Contributions: Writing original draft preparation, S.K.; writing review and editing, S.K. and O.L. Both authors have read and agreed to the published version of the manuscript.

Funding: This research received no external funding.

Institutional Review Board Statement: Not applicable.

Informed Consent Statement: Not applicable.

Data Availability Statement: Not applicable.

Acknowledgments: The editors would like to thank all authors for their contributions to this Special Issue, and the reviewers for their constructive and valuable comments to improve the manuscripts.

Conflicts of Interest: The authors declare no conflict of interest.

\section{References}

1. Won, J.; Choi, J.; Lee, O.; Park, M.J.; Kim, S. Two Ways to Quantify Korean Drought Frequency: Partial Duration Series and Bivariate Exponential Distribution, and Application to Climate Change. Atmosphere 2020, 11, 476. [CrossRef]

2. Lee, C.W.; Park, M.J.; Yoo, D.G. Quantitative Determination Procedures for Regional Extreme Drought Conditions: Application to Historical Drought Events in South Korea. Atmosphere 2020, 11, 581. [CrossRef]

3. Sattar, M.; Jehanzaib, M.; Kim, J.; Kwon, H.-H.; Kim, T.-W. Application of the Hidden Markov Bayesian Classifier and Propagation Concept for Probabilistic Assessment of Meteorological and Hydrological Droughts in South Korea. Atmosphere 2020, 11, 1000. [CrossRef]

4. Mun, Y.-S.; Nam, W.-H.; Jeon, M.-G.; Bang, N.-K.; Kim, T. Assessment of Vulnerability to Drought Disaster in Agricultural Reservoirs in South Korea. Atmosphere 2020, 11, 1244. [CrossRef]

5. Tran, T.T.K.; Lee, T.; Shin, J.-Y.; Kim, J.-S.; Kamruzzaman, M. Deep Learning-Based Maximum Temperature Forecasting Assisted with Meta-Learning for Hyperparameter Optimization. Atmosphere 2020, 11, 487. [CrossRef]

6. Kim, E.-J.; Marzin, C.; Milton, S.; Boo, K.-O.; Kim, Y.; Oh, J.; Kang, H.-S. Representation of the 2016 Korean Heatwave in the Unified Model Global NWP Forecasts: The Impact of Remotely Forced Model Errors and Atmosphere-Ocean Coupling. Atmosphere 2020, 11, 1275. [CrossRef]

7. Jo, S.; Shim, K.-M.; Hur, J.; Kim, Y.-S.; Ahn, J.-B. Future Changes of Agro-Climate and Heat Extremes over S. Korea at 2 and $3{ }^{\circ} \mathrm{C}$ Global Warming Levels with CORDEX-EA Phase 2 Projection. Atmosphere 2020, 11, 1336. [CrossRef]

8. Watson, P.; Lim, H.-S. An Update on the Status of Mean Sea Level Rise around the Korean Peninsula. Atmosphere 2020, 11, 1153. [CrossRef]

9. Song, M.-J.; Cho, Y.-S. Modeling Maximum Tsunami Heights Using Bayesian Neural Networks. Atmosphere 2020, 11, 1266. [CrossRef]

10. Sung, H.; Kim, J.; Lee, J.-H.; Shim, S.; Boo, K.-O.; Ha, J.-C.; Kim, Y.-H. Future Changes in the Global and Regional Sea Level Rise and Sea Surface Temperature Based on CMIP6 Models. Atmosphere 2021, 12, 90. [CrossRef]

11. Kim, H.; Han, K. Linking Hydraulic Modeling with a Machine Learning Approach for Extreme Flood Prediction and Response. Atmosphere 2020, 11, 987. [CrossRef] 
12. Seo, J.; Won, J.; Choi, J.; Lee, J.; Jang, S.; Lee, O.; Kim, S. Uncertainty of Rate of Change in Korean Future Rainfall Extremes Using Non-Stationary GEV Model. Atmosphere 2021, 12, 227. [CrossRef]

13. Lim, G.-K.; Kim, B.-S.; Lee, B.-H.; Jeung, S.-J. Effect of Climate Change on Annual Precipitation in Korea Using Data Screening Techniques and Climate Change Scenarios. Atmosphere 2020, 11, 1027. [CrossRef]

14. Sun, M.-A.; Sung, H.M.; Kim, J.; Lee, J.-H.; Shim, S.; Boo, K.-O.; Byun, Y.-H.; Marzin, C.; Kim, Y.-H. Reversibility of the Hydrological Response in East Asia from $\mathrm{CO}_{2}$-Derived Climate Change Based on CMIP6 Simulation. Atmosphere 2021, 12, 72. [CrossRef] 